\title{
Study of the Interaction Between Water and Gelidium sesquipedale (Rhodophyta): Part II: Kinetic of the Drying Process
}

\author{
Moulay Chrif Hnini ${ }^{1}$, M'barek Benchanaa ${ }^{1} \&$ Mustapha El Hammioui ${ }^{1}$ \\ ${ }^{1}$ Laboratoire de Recherche sur la Réactivité des Matériaux et l'Optimisation des Procédés-REMATOP, Faculté \\ des Sciences Semlalia Marrakech, Université Caddi Ayyad, Boulevard Prince My Abdellah, Marrakech, Morocco \\ Correspondence: M'barek Benchanaa, Laboratoire de Recherche sur la Réactivité des Matériaux et \\ l'Optimisation des Procédés-REMATOP, Faculté des Sciences Semlalia Marrakech, Université Caddi Ayyad, \\ Marrakech, Morocco. Tel: 212-6-6119-2039. E-mail: mbarek_benchanaa@yahoo.fr
}

Received: October 14, 2013 Accepted: April 21, 2014 Online Published: April 25, 2014

doi:10.5539/ijc.v6n2p82 URL: http://dx.doi.org/10.5539/ijc.v6n2p82

\begin{abstract}
The study of drying of red alga (Gelidium sesquipedale, Rhodophyta), with initial sample masses varying from 1 to $10 \mathrm{~g}$, was carried at different temperatures $30-80^{\circ} \mathrm{C}$. The experimental drying curves show a slight effect of the initial mass. Two types of curves are obtained: those at temperatures below $50^{\circ} \mathrm{C}$ are fitted into straight line according to an interfacial progression process in cylindrical symmetry. Those of high-temperature drying $(50<$ $\theta<80^{\circ} \mathrm{C}$ ), are perfectly parabolic and show that the kinetic regime is controlled by the three-dimensional diffusion according to the Jander equation. The two types of water molecules identified were also highlighted during the drying kinetics process. The apparent activation energy of the strongly bounded water $(20 \%)$ is about $36.25 \mathrm{~kJ} \cdot \mathrm{mol}^{-1}$, and that of the wetting water is in the range of $47.68 \mathrm{~kJ} \cdot \mathrm{mol}^{-1}$.
\end{abstract}

Keywords: Gelidium sesquipedale, drying kinetic, rate of progress, regulating process, apparent activation Energy

\section{Introduction}

Seaweed has attracted considerable attention as a potential source for several applications and is the subject of several studies (Corrigan, 1995; Miyagawa et al., 1995; Usov, 1998; Bannov et al., 1998; Ait Mohamed, 2005; Wang et al., 2009; Ye et al., 2010, etc.). Moroccan coasts are rich in red algae. Gelidium sesquipedale is the primary source for the production of agar, highly recommended product in the food industry. The industrial process for preparing the agar is always preceded by the step of storing the red algae which depends on ways and technology used in the drying phase.

In a previous studies (Hnini et al., 2013), we have presented the experimental results concerning the thermodynamic equilibrium of the sorption and desorption of water in red algae. The main aim was to understand the nature of the interaction between water molecules and the Gelidium sesquipedale. The sorption and desorption isotherms were performed using the static gravimetric method at temperatures 30,45 , and $60{ }^{\circ} \mathrm{C}$ and showed a slight hysteresis. In this study, the thermodynamic aspects has allowed to understand that $20 \%$ of water molecules are strongly linked to potential adsorption sites inside the plant cells and $80 \%$ of water molecules constitutes dampening water (Hnini et al., 2013).

To better control the behavior of the Gelidium sesquipedale with water, and to determine the optimal conditions for storage of dried seaweed, we study in this work the kinetic drying of Gelidium sesquipedale by conventional heating in order to understand:

- the influences of temperature and initial sample mass on drying;

- the mechanism that regulates the drying process and the kinetic parameters which can be used for modeling and optimization of the drying processes.

These results will be also compared in a further work, with those achieved under the same conditions of drying by the application of microwave technology. This comparison will allow us to better understand the interaction between water and the algae during the drying process. 


\section{Controlled Process}

Drying is the unit operation that aims to eliminate a liquid wetting a solid by evaporation. The study of the drying process of the alga by conventional heating results in monitoring the evolution of the mass of water desorbed $\mathrm{m}_{\mathrm{d}}(\mathrm{t})$ (Figure 1) versus time for different temperatures.

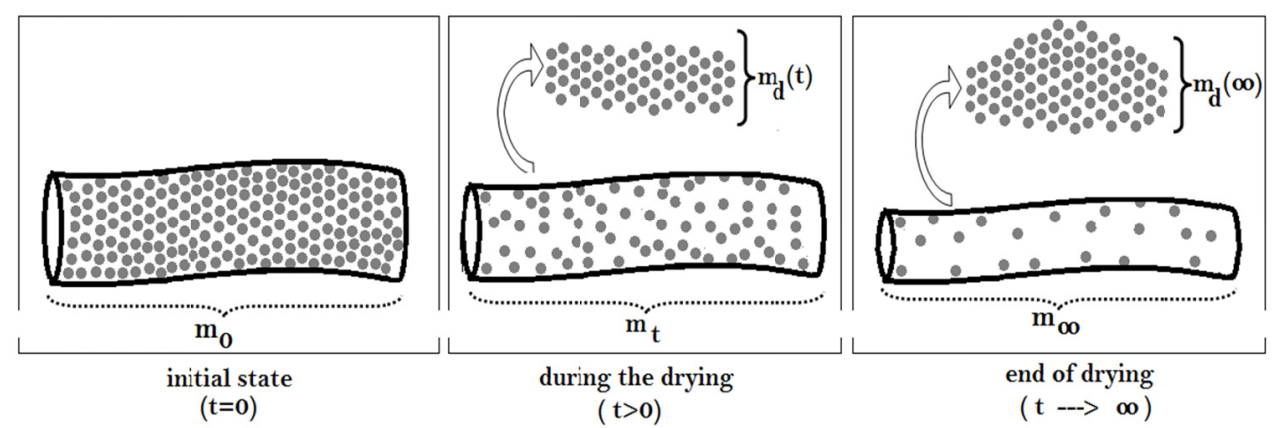

Figure 1. Stages of drying of a Gelidium Sesquipedale stem

The curves could be plotted using the rate progress $\alpha$ defined as:

$$
\alpha=\frac{m_{0}-m_{t}}{m_{0}-m_{\infty}}=\frac{m_{d}(t)}{m_{d}(\infty)} \quad 0 \leq \alpha \leq 1
$$

with $m_{0}$ is the initial mass of the sample, $m_{t}$ and $m_{\infty}$ are respectively the sample mass at time $t$ and at the end of drying. $\mathrm{m}_{\mathrm{d}}(t)$ and $\mathrm{m}_{\mathrm{d}}(\infty)$ represent the mass of water desorbed at time $t$ and at the end of drying process.

The rate equation with separate variables that allows to determine the kinetic parameters can be defined by:

$$
\frac{d \alpha}{d t}=K(T) \cdot f(\alpha) \cdot g(\alpha, T) \cdot h(\Gamma)
$$

where $f(\alpha)$ depends on the type of rate-controlling process, $K(T)$ is the temperature-dependent rate constant, $g(\alpha$, $\mathrm{T})$ is a function that reflects the interaction between the temperature and the rate progress; $h(\Gamma)$ is a function of all other parameters that can intervene and change the kinetic process (pressure, geometric properties, storage conditions, etc.).

When the rate of a reaction is governed by a single limiting step, the functions $g(\alpha, T)$ and $h(\Gamma)$ are constant. The evolution with time of the rate progress $\alpha$, is described by a differential equation of the form:

$$
\frac{d \alpha}{d t}=k(T) \cdot f(\alpha)
$$

The integration of Equation (3) leads to the function $F(\alpha)$, given by:

$$
F(\alpha)=\int_{0}^{\alpha} \frac{d \alpha}{f(\alpha)}=\int_{0}^{t} k(T) \bullet d t=k(T) \bullet t
$$

The comparison of the experimental drying curves, using the rate progress, with theoretical curves derived from kinetic models, allows information on the kinetics of the drying process (Šesták \& Málek, 1993; Koga et al., 1993; Bezjak et al., 2002; Šimon, 2005, 2011; Roura \& Farja, 2009; Daneshvar et al., 2012). Sharp et al. (1966) have published an article in which they identify several transformation models presented in Table 1. For a given model, if the experimental results show a linear evolution of $F(\alpha)$ versus time, this function then expressed the kinetic mechanism of the considered transformation. 
Table 1. Kinetic laws reported by Sharp et al. (1927) and used for the determination of reaction mechanisms in heterogeneous kinetics

\begin{tabular}{cccc}
\hline Symbole & $\mathrm{f}(\alpha)$ & $\mathrm{F}(\alpha)$ & Controlled process \\
\hline $\mathrm{F}_{1}$ & $(1-\alpha)$ & $-\ln (1-\mathrm{a})$ & Hazardous germination \\
$\mathrm{R}_{2}$ & $(1-\alpha)^{1 / 2}$ & $2\left[1-(1-\alpha)^{1 / 2}\right]$ & Interfacial progression in cylindrical symmetry \\
$\mathrm{R}_{3}$ & $(1-\alpha)^{2 / 3}$ & $3\left[1-(1-\alpha)^{1 / 3}\right]$ & Interfacial progression in spherical symmetry \\
$\mathrm{D}_{1}$ & $1 / 2 \alpha$ & $\alpha^{2}$ & Monodimensionnal diffusion \\
$\mathrm{D}_{2}$ & $-1 / \ln (1-\alpha)$ & $(1-\alpha) \ln (1-\alpha)+\alpha$ & Bidimensionnal diffusion \\
$\mathrm{D}_{3}$ & $3(1-\alpha)^{2 / 3} /\left(2\left[1-(1-\alpha)^{1 / 3}\right]\right)$ & {$\left[1-(1-\alpha)^{1 / 3}\right]^{2}$} & Tridimensionnal diffusion (Jander equation) \\
$\mathrm{D}_{4}$ & $3 /\left(2\left[(1-\alpha)^{-1 / 3}-1\right]\right)$ & $1-2 \alpha / 3-(1-\alpha)^{2 / 3}$ & Tridimensionnal diffusion (Ginstling-Broushtein \\
& & & equation) \\
\hline
\end{tabular}

\section{Materials and Experimental Techniques}

\subsection{Studied Materials}

The studied samples of Gelidium sesquipedale are from the Atlantic coast (Safi-Morocco). The sample preparation and the storage conditions have been described in a previous work (Hnini et al., 2013).

\subsection{Experimental Techniques}

As shown in Figure 2, the thermogravimetric assembly used consists of a precision balance (accuracy $0.1 \mathrm{mg}$ ) combined with a drying oven (WTC Binder) in which a sample is suspended. The drying experiments were carried out under atmospheric pressure at different temperatures ranging from 30 to $80{ }^{\circ} \mathrm{C}$ and for different initial masses $\mathrm{m}_{0}$ of the sample ( 1 to $10 \mathrm{~g}$ ). Monitoring the evolution of the mass of the sample at different times is performed at constant temperature and the experiment is completed when the sample mass is unchanged. The experiments were done several times to ensure reproducibility of results.

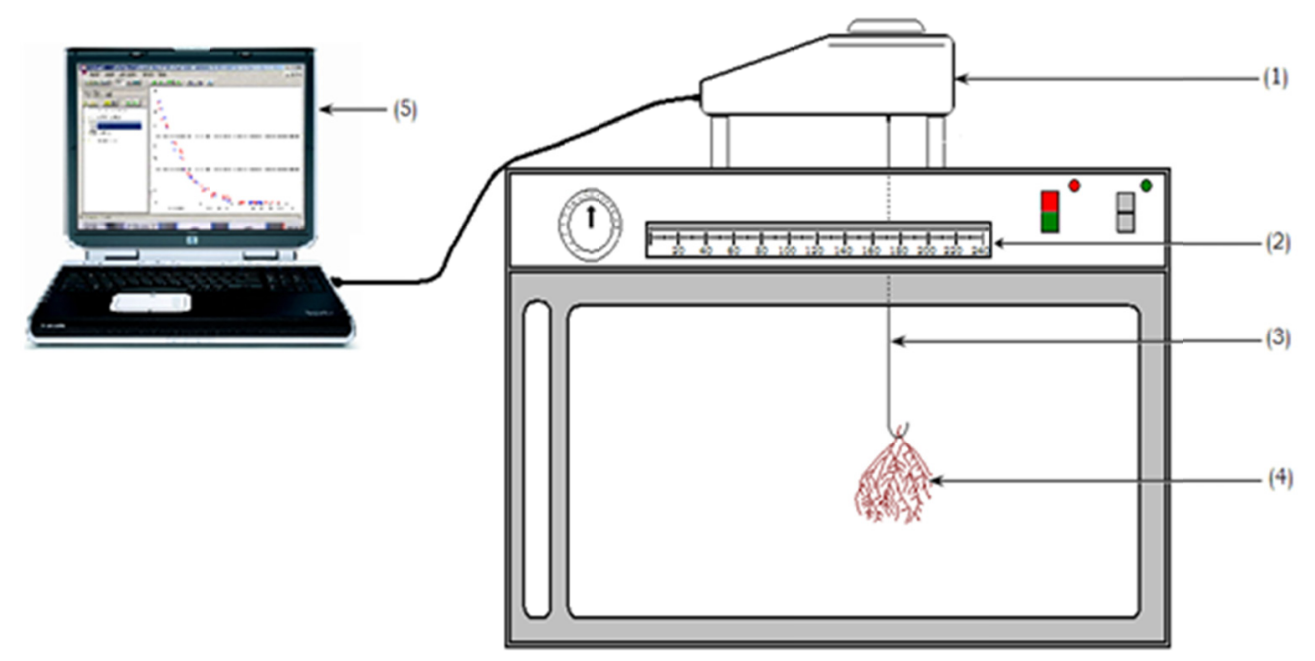

Figure 2. Experimental device used during the conventional drying: (1) Balance, (2) Thermometer, (3) Suspension rod, (4) Sample, (5) Collected data

\section{Experimental Results}

\subsection{Kinetic Curves of Drying}

Figures 3 and 4 show respectively the evolution of the amount of water desorbed $m_{d}(t)$ and the instantaneous 
speed of drying $(\mathrm{d} \alpha / \mathrm{dt})$ versus time at different temperatures:

- $\quad$ All curves obtained at different temperatures converge to the same level corresponding to the complete drying of the sample (desorption equilibrium). For samples with $\mathrm{m}_{0}=1.83 \mathrm{~g}$, the amount of desorbed water is $1.34 \mathrm{~g}$ (corresponding to $73 \%$ of water lost).

- For all temperatures, the desorption rate is continuously decreasing: the drying rate is maximum at $\mathrm{t}=0$, decreases and tends towards a limit value at the end of the experiment.

- $\quad$ The shape of the drying curve change with temperature.

The initial rate of drying (Figure 5) is strongly influenced by the temperature imposed, it increases with temperature according to the Arrhenius law.

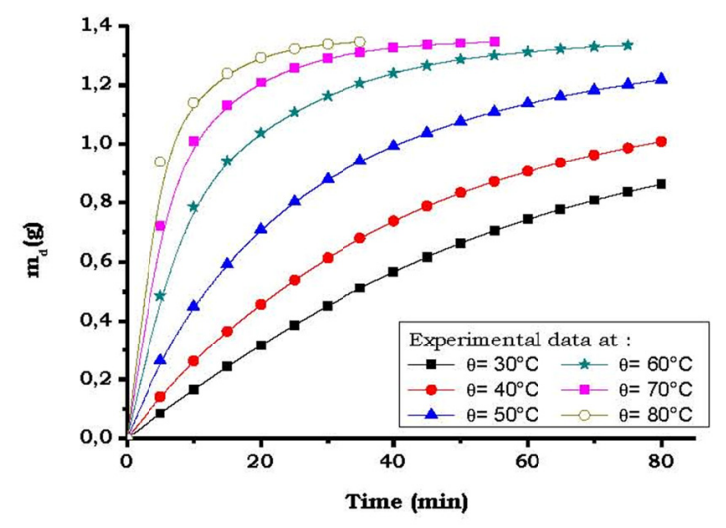

Figure 3. Evolution of the amount of water desorbed versus time at different temperatures $\left(\mathrm{m}_{0}=1.83 \mathrm{~g}\right)$

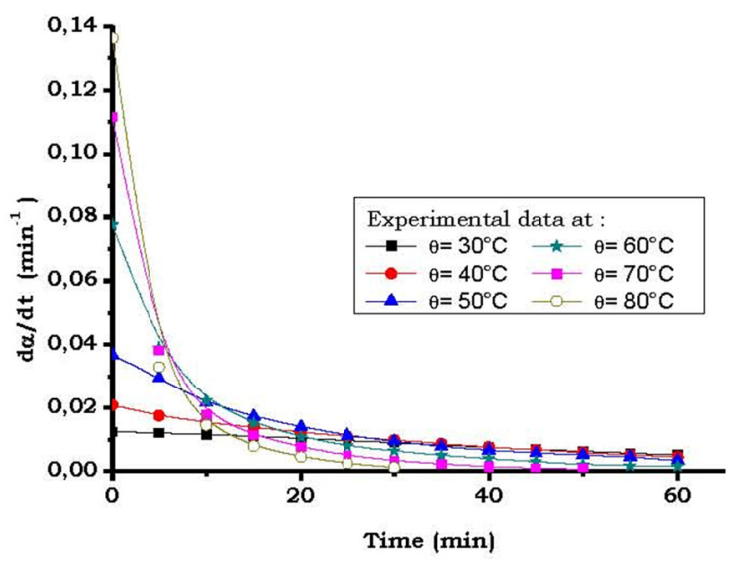

Figure 4. Instantaneous speed of drying versus time at different temperatures $\left(\mathrm{m}_{0}=1.83 \mathrm{~g}\right)$ 


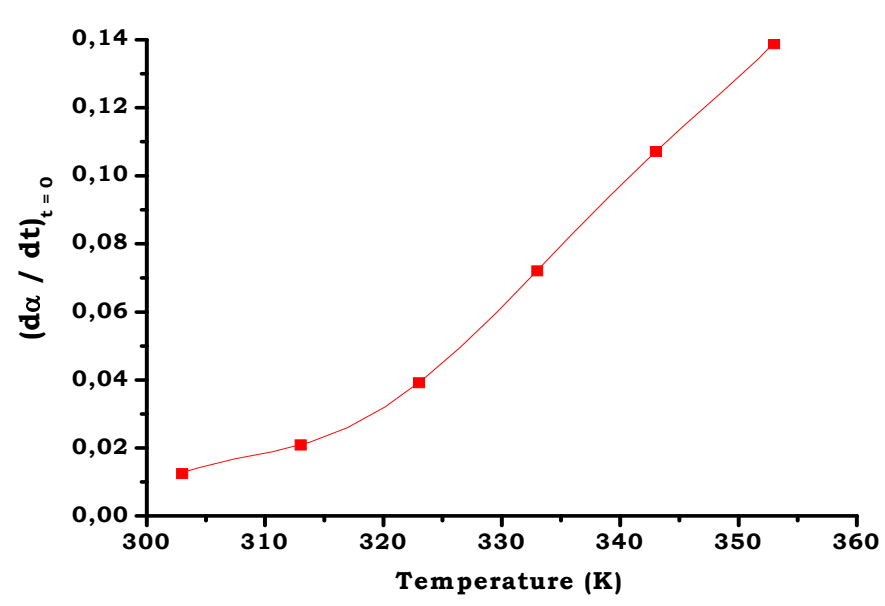

Figure 5. Initial speed of drying versus time at different temperatures $\left(\mathrm{m}_{0}=1.83 \mathrm{~g}\right)$

The results obtained in this study can be compared with those obtained by Bakass et al. (1997) for the adsorption and the desorption of water vapor on a superabsorbent polymer, Aouad et al. (2006) during the drying of phosphates black and Aouad et al. (2002) during the decomposition of natural phosphate and its kerogen.

Figures 6 and 7 show respectively the variation of extent of conversion $\alpha$ and the instantaneous speed of drying versus time at $60^{\circ} \mathrm{C}$, for samples that have different initial masses (from 1 to $10 \mathrm{~g}$ ). The analysis of these results show that for the initial masses used, the rate of desorption is continuously decreasing and the curves converge to the level $\alpha=1$ even faster than the initial mass of the sample decreases.

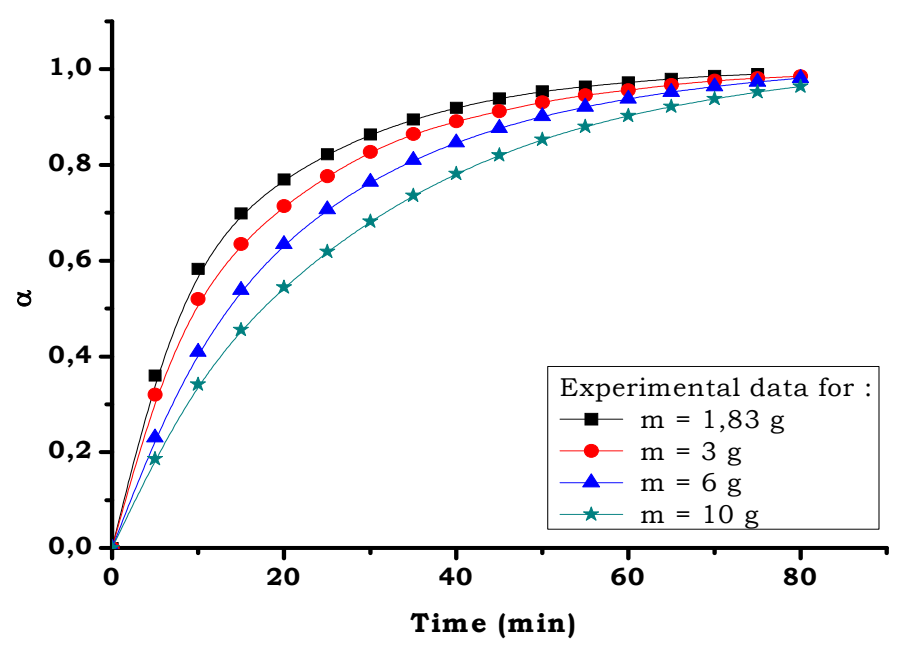

Figure 6. Evolution of the rate progress of the drying process at $60^{\circ} \mathrm{C}$ for samples that have different initial masses 


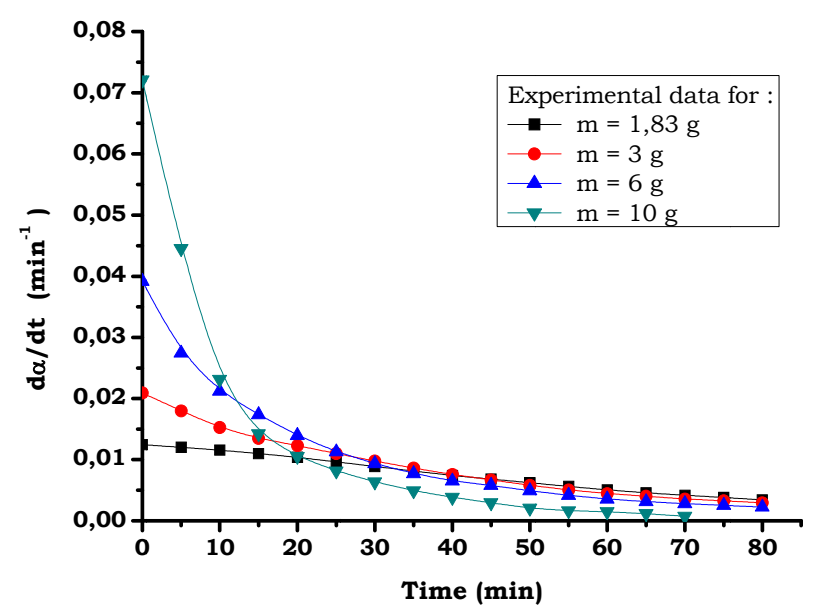

Figure 7. Instantaneous speed of drying versus time for different initial masses at $60{ }^{\circ} \mathrm{C}$

\subsection{Kinetic Regime Controlling the Drying Process}

To determine the kinetic process that controls the drying of the Gelidium sesquipedale we plotted the evolution of the function $F(\alpha)$ as a function of time. As shown in Figures 8 and 9, the results indicate that:

- $\quad$ For temperatures lower than $50{ }^{\circ} \mathrm{C}$, the experimental curves $\alpha=\mathrm{f}(\mathrm{t})$ are better linearized according to the law: $F(\alpha)=1-(1-\alpha)^{1 / 2}$. These transformed drying curves show that the dominant drying is a progression interfacial cylindrical symmetry.

- $\quad$ For temperature higher than $50{ }^{\circ} \mathrm{C}$, the experimental curves $\alpha=\mathrm{f}(\mathrm{t})$ are better linearized according to the dependent kinetic model function: $F(\alpha)=\left[1-(1-\alpha)^{1 / 3}\right]^{2}$. This law shows that the drying process is controlled by a diffusion régime according to the Jander equation (Jander, 1927).

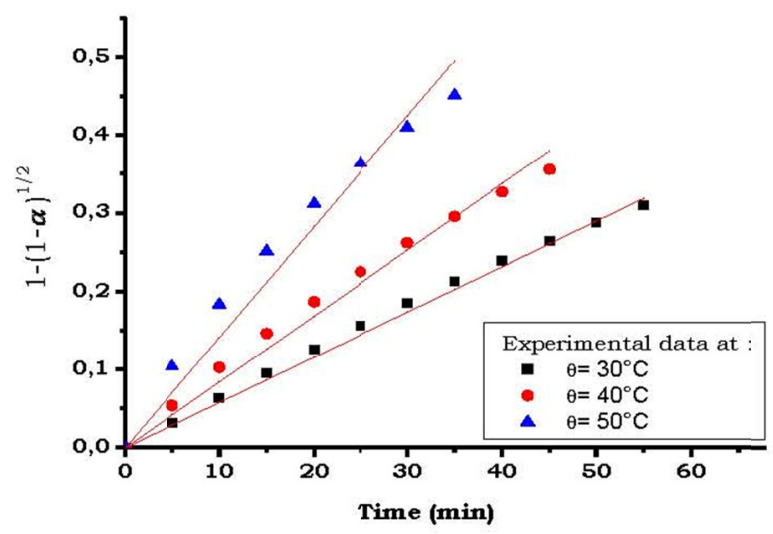

Figure 8. Transformed drying curves according to the $F(\alpha)=1-(1-\alpha)^{1 / 2}$ law at different temperatures 


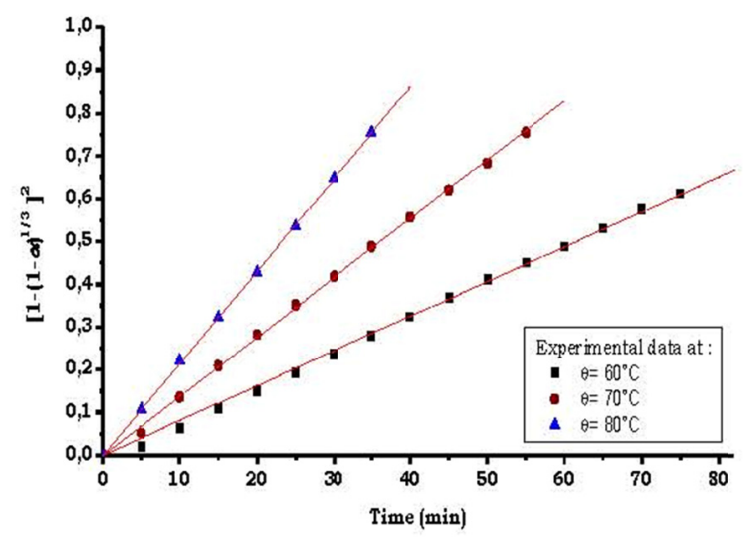

Figure 9. Transformed drying curves according to the $F(\alpha)=\left[1-(1-\alpha)^{1 / 3}\right]^{2}$ law at different temperatures

The analysis of the transformed drying curves show that there is an Arrhenius type dependency between the rate constant $\mathrm{k}(\mathrm{T})$ and temperature according to:

$$
k(T)=A \cdot \exp \left(-\frac{E_{a}}{R T}\right)
$$

where $\mathrm{A}$ is the pre-exponential factor or frequency factor and $\mathrm{E}_{\mathrm{a}}$ the apparent activation energy.

According to the temperature range, the evolution of the rate constant (Table 2) obtained with the slopes of the transformed drying curves (Figure 10) provide two values of the apparent energy of activation: $36.25 \mathrm{~kJ} \cdot \mathrm{mol}^{-1}$ for temperatures lower than $50{ }^{\circ} \mathrm{C}$ and $47.68 \mathrm{~kJ} \cdot \mathrm{mol}^{-1}$ for temperatures higher than $50{ }^{\circ} \mathrm{C}$.

Table 2. Rate constant corresponding to different temperatures

\begin{tabular}{lcccccc}
\hline$\theta\left({ }^{\circ} \mathrm{C}\right)$ & 30 & 40 & 50 & 60 & 70 & 80 \\
\hline $\mathrm{k}(\mathrm{T}) \cdot 10^{3}\left(\mathrm{mn}^{-1}\right)$ & 5,796 & 8,436 & 14,156 & 8,12 & 13,82 & 21,53 \\
\hline
\end{tabular}

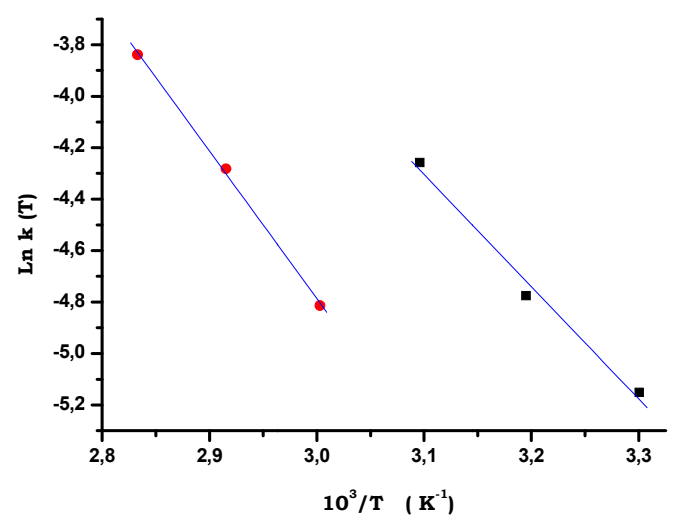

Figure 10. Variation of $\operatorname{Lnk}(\mathrm{T})$ as a function of $(1 / \mathrm{T})$

\section{Discussion}

In this experimental study, the drying of Gelidium sesquipedale by conventional thermal heating highlights the influence of the parameters studied, namely the drying temperature and the initial mass of the sample, on the desorption kinetics of water of red algae.

All experimental results are reproducible and indicate the conditions and mechanisms of drying for different 
initial masses. These experimental results can be described by models of heterogeneous kinetics (Table 1). Their application to the experimental curves $\alpha(t)$ can show that they are properly linearized according to mathematical laws that reflect the predominance of a kinetic regime depending on the progress of drying. These models were applied to describe the effects of temperature and the initial mass of the sample on the drying kinetics.

The analysis of all these results can bring information on the mechanisms of drying and confirm the nature of water molecules defined previously (Hnini et al., 2013). We should note that the kinetic mechanism that regulates the drying process is not pure, two kinetic regimes have been identified in this work: progression in interfacial cylindrical symmetry at low temperatures $\left(\theta<50{ }^{\circ} \mathrm{C}\right.$, range I) and diffusion at high temperature $\left(50{ }^{\circ} \mathrm{C}<\theta<80^{\circ} \mathrm{C}\right.$, range II). We note that the predominance of one regime to another depends not only on the imposed temperature, but also on mechanical phenomena that occur during the drying as shown in Figure 11. This figure defers the curves obtained during drying performed under conditions of temperatures corresponding to ranges I and II, and secondly, the evolution of the morphology of the seaweed fibers in the beginning, during and at the end of drying experience.

The drying process studied here is complex because the desorption of water molecules of the seaweed is associated with the geometric deformation of the fibers during the process. The apparent activation energies, determined by the slopes of the linear transforms, include in addition to the true value of the activation energy of the drying process, other values related to mechanical processes. Kinetic and morphological analyses can therefore show that:

- When the drying is carried out at low temperature (range I), the transfer of water molecules from inside to outside is linked to the heat transfer from the surface towards the inside of the cylindrical fibers of the algae. The overall transformation of drying is controlled by an interfacial growth regime. This regime, predominant during the first forty minutes, continues despite the deformations caused by mechanical deformation produced during drying of cylindrical fibers of the seaweed studied.

- When the drying is carried out at temperatures above (range II), the heat transfer to the heart of the fibers is fast and the heating of water molecules in the interior is also very fast. Drying is carried out rapidly with mass transfer influenced by the effect of temperature imposed. The global phenomenon is then controlled by the three-dimensional diffusion characterized by the linearization of the experimental curves according to Jander's law. We note that this diffusive regime is also dominated by the mechanical phenomena that start in the opening minutes.

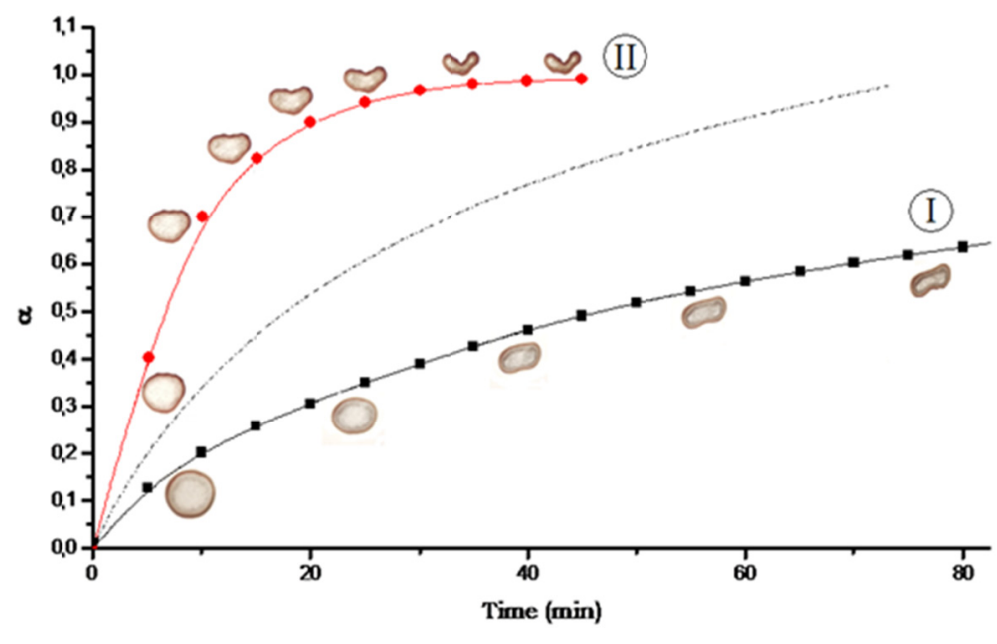

Figure 11. Shape of the drying curves in both temperature ranges

All these results also state that the apparent activation energy depends on the temperature and the manner in which heat is transferred to the seaweed. The values of the apparent activation energy obtained in the conditions corresponding to drying ranges I and II are different. It is small at low temperature and the difference between the apparent activation energies could be explained, firstly, by the difference of the mechanisms involved, and secondly, by the mechanical phenomena that begin early in domain II and delay in domain I. 


\section{Conclusion}

In this work we are interested to studying the drying kinetics of the Gelidium sesquipedale under different temperatures and for different initial masses. Two main objectives were set at the beginning:

- The determination of the effects of temperature and initial mass of the sample,

- The knowledge of the mechanism that can regulate the drying process and the kinetic parameters that can be used for modeling and optimizing the drying process.

From the analysis of all results, we can note:

- For a given initial mass of the sample, the temperature has a significant influence on drying. Its effect is manifested by increasing the speed of drying when the temperature increases.

- For a fixed temperature, the initial mass of the sample has a slight influence on the rate of drying. In the area of initial mass studied the drying mechanism remains the same.

- The drying of samples occurs by mechanisms that depend on temperature: interfacial progression at low temperatures (range I) and diffusion at high temperatures (range II). During the drying process, these two mechanisms occur with the start of the water desorption, but at high temperature, they compete with mechanical phenomena that begin over early.

The drying kinetics is influenced by temperature but also the way in which heat transfer takes place within the algae. These results encourage us to undertake a further systematic study on the drying process under microwave irradiation. This technology is now playing an important role in energy optimization of industrial processes and drying at the quality of dried products.

\section{References}

Ait Mohamed, L., Kouhila, M., Lahsasni, S., Jamali, A., Idlimam, A., Rhazi, M., ... Mahrouz, M. (2005). Equilibrium moisture content and heat of sorption of Gelidium sesquipedale. Journal of Stored Products Research, 41(2), 199-209. http://dx.doi.org/10.1016/j.jspr.2004.03.001

Aouad, A., Benchanaa, M., El Harfi, K., \& Mokhlisse, A. (2006). Effects of acid treatments on the mineral and organic matter contents of sedimentary phosphate. Annales de Chimie - Sciences des Matériaux, 31(1), 1-10. http://dx.doi.org/10.3166/acsm.31.1-10

Aouad, A., Bilali, L., Benchanâa, M., \& Mokhlisse, A. (2002). Kinetic Aspect of Thermal Decomposition of Natural Phosphate and its Kerogen. Influence of heating rate and mineral matter. Journal of Thermal Analysis and Calorimetry, 67(3), 733-743.

Bakass, M., Mokhlisse, A., \& Lallemant, M. (1997). Adsorption et désorption de l'eau vapeur sur un polymère polyacrylique superabsorbant. IV. Effet de la masse sur les cinétiques d'adsorption et de désorption. Thermochimica Acta, 290(2), 227-238. http://dx.doi.org/10.1016/0040-6031(95)02785-8

Barinov, G. V., Lopukhin, A. S., \& Trenckenshu, R. E. (1998). Respiration energetics of marine algae for total heat production and some features of photosynthesis. Thermochimica Acta, 309(1-2), 133-138. http://dx.doi.org/10.1016/S0040-6031(97)00355-9

Bezjak, A., Kurajica, S., \& Šipušić, J. (2002). A new approach to solid-state reactions kinetics analysis: The application of assisting functions to basic equations for isothermal conditions. Thermochimica Acta, 386(1), 81-90. http://dx.doi.org/10.1016/S0040-6031(01)00770-5

Corrigan, O. I. (1995). Thermal analysis of spray dried products. Thermochimica Acta, 248, 245-258. http://dx.doi.org/10.1016/0040-6031(94)01891-J

Daneshvar, S., Salak, F., \& Otsuka, K. (2012). Pyrolytic behavior of green macro algae and evaluation of its activation energy. International Journal of Chemical Engineering and Applications, 3(4), 256-263. http://dx.doi.org/10.7763/IJCEA.2012.V3.196

Hnini, M. C., Benchanaa, M., \& El Hammioui, M. (2013). Study of the interaction between water and Gelidium sesquipedale (Rhodophyta). Part I: Thermodynamic aspect of the sorption equilibrium. Journal of the Taiwan Institute of Chemical Engineers, 44, 795-801. http://dx.doi.org/10.1016/j.jtice.2013.01.023

Jander, W. (1927). Reactions in the solid state at high temperature. Zeitschrift fur anorganische und allgemeine Chemie, 163(1), 1-30. http://dx.doi.org/10.1002/zaac.19271630102

Koga, N., Malek, J., Sestak, J., \& Tanaka, H. (1993). Data treatment in non-isothermal kinetics and diagnostic limits of phenomenological models. Netsu Sokutei, 20(4), 210-223. http://hdl.handle.net/11104/0058551 
Miyagawa, K., Ogawa, I., \& Yamano, H. (1995). Calorimetric measurements on the swelling of seaweed. Thermochim Acta, 257, 75-82. http://dx.doi.org/10.1016/0040-6031(94)02198-W

Roura, P., \& Farja, J. (2009). Analytical solution for the Kissinger equation. Journal of Materials Research, 24(10), 3095-3098. http://dx.doi.org/10.1557/jmr.2009.0366

Šesták, J., \& Málek, J. (1993). Diagnostic limits of phenomenological models of heterogeneous reactions and thermal analysis kinetics. Solid State Ionics, $245-254$. http://dx.doi.org/10.1016/0167-2738(93)90113-H

Sharp, J. H., Brindley, G. W., \& Narahari Achar, B. N. (1966). Numerical data for some commonly used solid state reaction equations. Journal of American Ceramic Society, 49(7), $379-382$. http://dx.doi.org/10.1111/j.1151-2916.1966.tb13289.x

Šimon, P. (2005). Considerations on the single-step kinetics approximation. Journal of Thermal Analysis and Calorimetry, 82(3), 651-657. http://dx.doi.org/10.1007/s10973-005-0945-6

Šimon, P. (2011). Fourty years of the Šesták-Berggren equation. Thermochimica Acta, 520, $156-157$. http://dx.doi.org/10.1016/j.tca.2011.03.030

Usov, A. I. (1998). Structural analysis of red seaweed galactans of agar and carrgeenan groups. Food Hydrocolloids, 12(3), 301-308. http://dx.doi.org/10.1016/S0268-005X(98)00018-6

Wang, S., Jiang, X. M., Han, X. X., \& Liu, J. G. (2009). Combustion Characteristics of Seaweed Biomass. 1. Combustion characteristics of Enteromorpha clathrata and Sargassum natans. Energy Fuels, 23, 5173-5178. http://dx.doi.org/10.1021/ef900414x

Ye, N., Li, D., Chen, L., Zhang, X., \& Xu, D. (2010). Comparative studies of the pyrolytic and kinetic characteristics of maize straw and the seaweed Ulva pertusa. PLoS One, 5(9), e12641. http://dx.doi.org/10.1371/journal.pone.0012641

\section{Copyrights}

Copyright for this article is retained by the author(s), with first publication rights granted to the journal.

This is an open-access article distributed under the terms and conditions of the Creative Commons Attribution license (http://creativecommons.org/licenses/by/3.0/). 